\title{
Coexistence of intervertebral disc herniation with intradural schwannoma in a lumbar segment: a case report
}

\author{
Jianjiang Pan ${ }^{1}$, Yue Wang ${ }^{1 *}$ and Yazeng Huang ${ }^{2^{*}}$
}

\begin{abstract}
Background: Lumbar intervertebral disc herniation and spinal tumor are major pathologies that may cause back pain and radiculopathy. Neurological symptoms resulting from disc herniation and intradural spinal tumor together, however, are very rare.

Case presentation: We report a case of lumbar disc herniation which coexists with intradural schwannoma at the same spinal level in a 67-year-old man. The patient presented with persistent low back pain, sciatica, and weakness of the lower limbs. Contrast lumbar spine magnetic resonance (MR) imaging clearly delineated an intradural lesion and an extradural herniated disc at L3/4 level. Using a single posterior approach, both pathologies were addressed.

Pathological studies confirmed the intradural lesion was schwannoma.

Conclusion: The case report highlights a rare concomitance of two symptomatic pathologies in a lumbar spine, which deserves clinical attention. Complete history, careful physical examination, and investigative measures, such as contrast MR imaging, are helpful to establish throughout diagnoses.
\end{abstract}

Keywords: Lumbar disc herniation, Intraspinal tumor, Schwannoma

\section{Background}

Lumbar intervertebral disc herniation is one of the most common spinal disorders that cause back pain and radiating leg pain [1]. Spinal tumor is another category of major pathologies that may lead to pain and neurological symptoms [2]. Occasionally, extradural or intradural tumor may present clinical symptoms similar to those of disc herniation, with confusing image findings. It is, however, rare for the two pathologies to present at the same spinal level. We reported such a case of L3/4 disc herniation coexisting with intradural schwannoma.

\section{Case presentation}

A 67-year-old man presented with low back pain, sciatica, and weakness of the lower limbs for 2 years. His back and leg pain exacerbated after standing or walking and relieved by lying supine with the knees and hips

\footnotetext{
*Correspondence: wangyuespine@gmail.com; huangyazeng@qq.com

${ }^{1}$ Spine Lab, Department of Orthopedic Surgery, The 1st Affiliated Hospital of Zhejiang University, 79\# Qingchun Road, Hangzhou 310003, China

2Department of Orthopedic Surgery, Zhejiang Provincial People's Hospital,

158\# Shangtang Road, Hangzhou 310014, China
}

flexed. Overall, his pain was tolerable. He can walk well, though he felt his legs were weaker than usual. $\mathrm{He}$ sought treatment at a local hospital, and magnetic resonance (MR) imaging revealed a herniation disc at L3/4 level. Two months ago, however, his back pain worsened considerably and he started to have intermittent claudication. His symptoms failed to respond to conservative treatments, and his walking distance decreased to approximately $100 \mathrm{~m}$. He was referred to us for further treatment. His bowel and bladder functions were normal since he was sick.

On physical examination, there was mild tenderness on L3-5 spinous processes. While straight leg raising test was negative, femoral stretch test was positive at both sides. Neurological examinations revealed decreased muscle power for the right quadriceps femoris and left tibialis anterior (Manual Muscle Test grade IV). His knee and ankle reflexes at the right leg disappeared, and sensation at the medial side of his left calf diminished. Pathological reflexes were negative at both legs. Lumbar spine MR imaging revealed an intradural lesion $(14 \times$ $8 \mathrm{~mm}^{2}$ ) at the left side of the dural sac and a herniated 

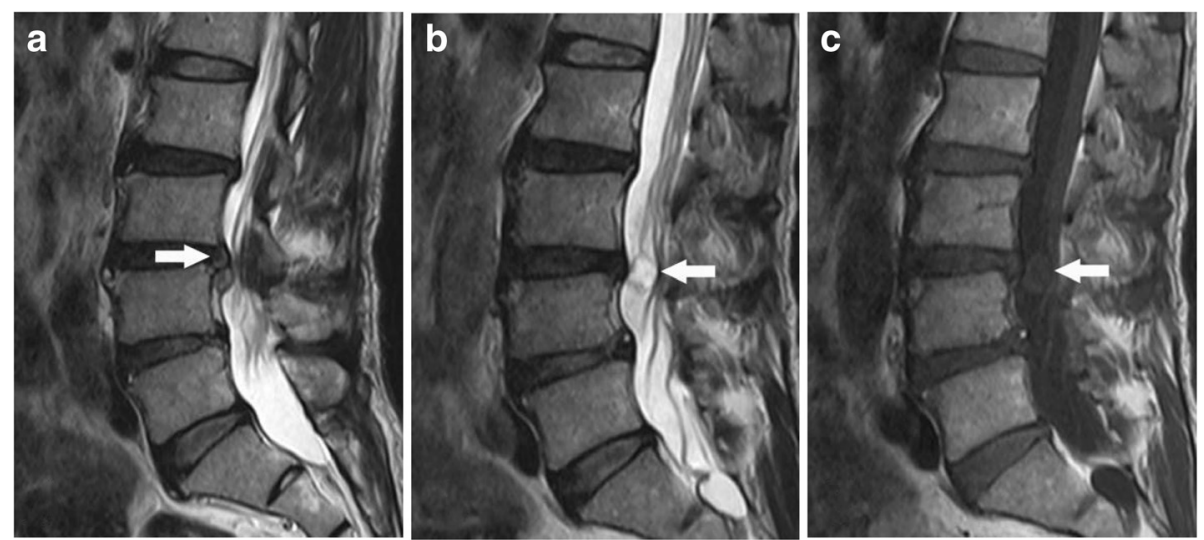

Fig. 1 T2-weighted sagittal image (a) revealed L3/4 disc herniation which compressed the dural sac from the right side. Two slices away, there was a hyperintense intradural mass at the same level (b). T1-weighted sagittal image (c) demonstrated a hypointense mass behind the L3/4 intervertebral disc

disc of moderate size at the right lateral recess of the L3/4 spinal canal (Figs. 1 and 2).

The patient underwent laminectomy and intrathecal tumor resection. Intraoperatively, the lesion was found to be encapsulated and stuck to a nerve root. After tumor removal, discectomy and posterior lumbar intervertebral fusion were performed. Histological studies revealed a herniated disc and a schwannoma. At the 6-month postoperative follow-up, the patient did not have back and leg pain. Neurological deficits at the extremities fully recovered, and he returned to normal life.

\section{Discussion}

The current case highlights a rare situation that symptomatic disc herniation and spinal tumor present simultaneously in a spinal segment. To our knowledge, there are only four similar cases of lumbar disc herniation coexisting with intradural tumor reported in English literatures [3-6]. Albert et al. reported a case of L4/5 disc herniation presented together with a neurinoma at the
L5 nerve root in a 52-year-old man [3]. The clinical manifestations revealed typical signs of L5 root compression from the herniated disc, and the tumor was an accidental finding on myelography. Liu et al. reported a 51-year-old man with L2/3 disc herniation coexisting with a schwannoma causing cauda equina syndrome [4]. The patient had suffered from low back pain for 3 years and was diagnosed with L2/3 lumbar disc herniation. To begin with, his back pain was relieved by conservative treatment but deteriorated progressively till cauda equina syndrome occurred. Bhatia et al. reported a paraganglioma coexisting with L5/S1 disc herniation in a 33year-old man [5]. The clinical presentation was left sciatica associated with paresthesia in the left S1 dermatome. In 2014, Baek et al. described another case of intradural schwannoma coexisting with lumbar disc herniation at L4/5 disc level in a 71-year-old woman who suffered from lower back pain and L5 radiculopathy [6]. Intrathecal tumor resection and discectomy were performed using a posterior approach in these cases. In our case,
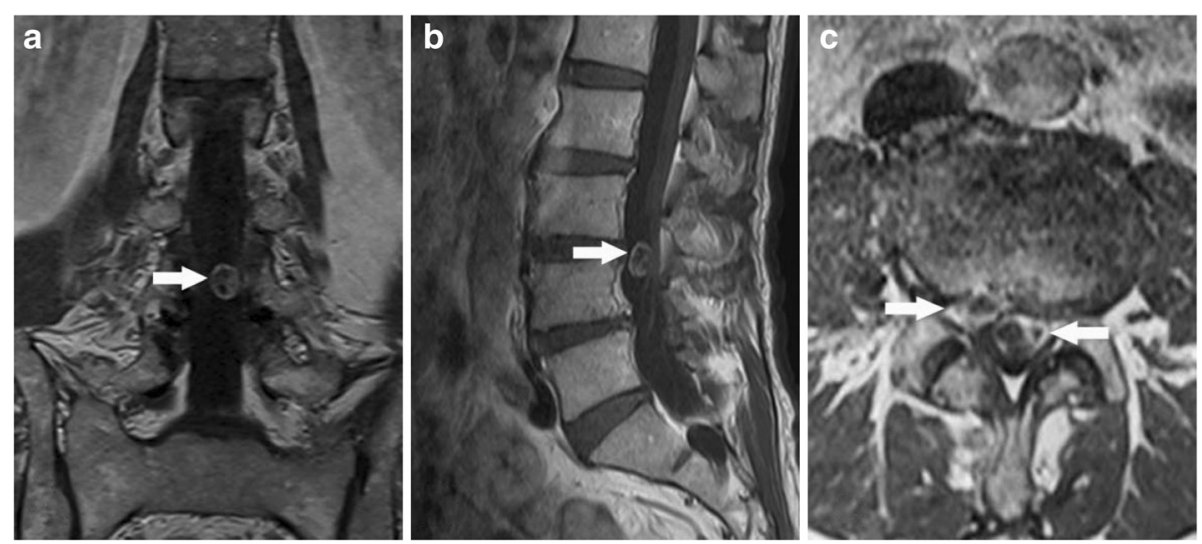

Fig. 2 Gadolinium contrast MR images (a coronal image, b sagittal image) demonstrated a partially enhanced intradural mass at the left side of the L3/4 spinal canal. Axial image (c) showed an intradural mass of heterogeneous signal at the left and a herniated disc at the right extradural space 
right leg radiculopathy resulted from L4 nerve root compression due to L3/4 disc herniation. Some other symptoms, such as claudication and leg weakness, may be the results of both pathologies. We used a single operation to address both conditions, as did others [4-6].

Spinal schwannoma is a benign nerve sheath tumor, which comprises approximately $15 \%$ of all spinal tumors [2]. The vast majority of schwannomas was located at the intradural space and occasionally presented as extradural or a dumbbell-shaped lesion [7]. Intradural schwannoma may produce symptoms similar to those of disc herniation, such as back pain and neurological deficits [8]. On MR images, schwannoma typically presents as an isolated and encapsulated mass, as hypointense or isointense on T1W images and hyperintense on T2W images [2]. Contrast MR imaging may reveal a well-delineated enhanced mass and, thus, is useful for differential schwannoma from disc degeneration [9]. In the present case, gadolinium contrast MR images revealed two heterogeneous signal masses at the same level, with one at the right extradural space and another at the left intradural space. As a result, the establishment of diagnosis was relatively easy.

In general, posterior epidural migration of a herniated lumbar disc fragment, a rare situation of disc herniation, should also be included in the differential diagnosis for extradural and intradural tumors [10-12]. Extradural disc fragment presents signals similar to those of a disc on both T1-weighted and T2-weighted MR sagittal images [11]. Moreover, disc fragment may demonstrate peripheral enhancement on contrast MR images $[10,11]$. Even rarer, calcified disc sequestration may mimic an intradural spinal tumor and had MR findings similar to that of schwannoma [13]. Occasionally, a histological study is the only way to verify the diagnosis.

When clinical symptoms cannot be fully explained by an identified pathology, the coexistence of another spinal pathology should be considered. It is easy to establish the diagnoses when a spinal tumor and a herniated disc present in the same spinal region, as both pathologies are displayed on a MR study. It is noteworthy, however, that spinal tumor and lumbar disc herniation may present at different spinal regions and a single MR study may not be able to reveal both. Knafa reported a patient who presented rapidly progressive spinal cord compression following discectomy [14]. Her symptoms temporally restored but soon developed progressing paralysis in her right leg. Retrospective MR revealed an extramedullary tumor at T1/2 level. Another scholar reported a similar case of misdiagnosed thoracic tumor with neurological deficits deteriorated after decompression surgery for lumbar spinal stenosis [15]. Symptoms of upper neuron compression in patients who suffer from lumbar degenerative disorders, therefore, should be carefully examined to exclude possible concomitant pathology in the thoracic or cervical regions.

\section{Conclusions}

We reported a rare case with disc herniation and spinal tumor present at the same spinal level. Due to the similarities of clinical presentations and image findings for spinal tumor and disc herniation, and at an early stage, a diagnosis of spinal tumor was missed in our case. We highlighted the possibilities of concomitant dual or epidural pathologies in some cases. Complete history, careful physical examination, and investigative measures, such as contrast MR imaging, are helpful to establish throughout diagnoses.

\section{Consent}

Written informed consent was obtained from the patient for the publication of this case presentation and accompanying images. A copy of the written consent is available for the review by the Editor-in-Chief of this journal.

Competing interests

The authors declare that they have no competing interests.

\section{Authors' contributions}

JP analyzed and interpreted the patient, drafted the manuscript, and created the figures. $\mathrm{YH}$ and $\mathrm{YW}$ performed the physical examination and provided the medical care. YH performed the histopathological examinations and made the diagnosis. YW supervised the entire case. All authors read and approved the final manuscript.

\section{Acknowledgements}

This study was supported by Zhejiang Medical Technology and Education Grant (2015ZDA014 and 2013KYB103).

Received: 30 January 2016 Accepted: 12 April 2016

Published online: 18 April 2016

\section{References}

1. Deyo RA, Weinstein JN. Low back pain. N Engl J Med. 2001;344(5):363-70.

2. Van Goethem JW, van den Hauwe L, Ozsarlak O, et al. Spinal tumors. Eur J Radiol. 2004;50(2):159-76.

3. Albert FK, Oldenkott $P$, Bieker $G$, et al. Lumbar intervertebral disk herniation with a concomitant nerve root neurinoma at the same site. Case report and review of the literature. Neurochirurgia. 1988;31(6):222-5.

4. Liu SY, Lin YM, Wei TS, et al. Exacerbation of symptoms of lumbar disc herniation complicated by a schwannoma: a case report. Kaohsiung J Med Sci. 2007;23(9):480-5.

5. Bhatia R, Jaunmuktane Z, Zrinzo A, et al. Caught between a disc and a tumour: lumbar radiculopathy secondary to disc herniation and filum paraganglioma. Acta Neurochir. 2013;155(2):315-7.

6. Baek SW, Kim C, Chang H. Intradural schwannoma complicated by lumbar disc herniation at the same level: a case report and review of the literature. Oncology letters. 2014;8(2):936-8.

7. Conti $P$, Pansini $G$, Mouchaty $H$, et al. Spinal neurinomas: retrospective analysis and long-term outcome of 179 consecutively operated cases and review of the literature. Surg Neurol. 2004;61(1):34-43. discussion 44.

8. Nambiar M, Kavar B. Clinical presentation and outcome of patients with intradural spinal cord tumours. J Clin Neurosci. 2012;19(2):262-6.

9. Friedman DP, Tartaglino LM, Flanders AE. Intradural schwannomas of the spine-MR findings with emphasis on contrast-enhancement characteristics. Am J Roentgenol. 1992;158(6):1347-50.

10. Eksi MS, Yener $U$, Akakin $A$, et al. Posterior epidural disc herniation at $L 3-L 4$ mimicking a spinal tumor: a case report. J Neurosurg Sci. 2010;54(2):71-6. 
11. Toktas ZO, Yilmaz B, Konya D, et al. Posterior epidural migration of lumbar disc fragment as an unusual ring-enhancing mass. Spine Journal. 2016;16(2): E31-2.

12. Liu CC, Huang $C T$, Lin CM, et al. Intradural disc herniation at L5 level mimicking an intradural spinal tumor. Eur Spine J. 2011;20:S326-9.

13. Song KJ, Kim KB, Lee KB. Sequestrated thoracic disc herniation mimicking a tumoral lesion in the spinal canal-a case report. Clin Imaging. 2012;36(4): 416-9.

14. Knafo S, Lonjon $\mathrm{G}$, Vassal $\mathrm{M}$, et al. Spinal cord compression due to undiagnosed thoracic meningioma following lumbar surgery in an elderly patient: a case report. Orthop Traumatol-Sur. 2013;99(8):983-6. doi:10.1016/j. otsr.2013.08.006. Published Online First: Epub Date.

15. Takeuchi A, Miyamoto K, Hosoe H, et al. Thoracic paraplegia due to missed thoracic compressive lesions after lumbar spinal decompression surgery-report of three cases. J Neurosurg. 2004;100(1):71-4.

Submit your next manuscript to BioMed Central and we will help you at every step:

- We accept pre-submission inquiries

- Our selector tool helps you to find the most relevant journal

- We provide round the clock customer support

- Convenient online submission

- Thorough peer review

- Inclusion in PubMed and all major indexing services

- Maximum visibility for your research

Submit your manuscript at www.biomedcentral.com/submit
Biomed Central 